\title{
Expression of $\mathrm{HDACl}$ and $\mathrm{CBP} / \mathrm{p} 300$ in human colorectal carcinomas
}

\author{
Katsuyoshi Ishihama, Mitsunori Yamakawa, Shuho Semba, Hiroaki Takeda, Sumio Kawata, Seishi \\ Kimura, Wataru Kimura
}

J Clin Pathol 2007;60:1205-1210. doi: 10.1136/icp.2005.029165

See end of article for authors' affiliations

.....................

Correspondence to:

Professor M Yamakawa,

Department of Pathology,

Yamagata University School

of Medicine, 2-2-2 lida-

Nishi, Yamagata 990-9585,

Japan; myamakaw@med.id.

yamagata-u.ac.jp

Accepted 15December 2005

Published Online First

24 August 2007
Background: The histone-modifying enzymes histone deacetylase (HDAC) and histone acetyltransferase (HAT) control gene transcriptional activation and repression in human malignancies.

Aims: To analyse the expression of HDAC/HAT-associated molecules such as $\mathrm{HDACl}$, CREB-binding protein (CBP) and p300 in human colorectal carcinomas, and investigate the relationship between their expression levels and clinicopathological parameters.

Methods: Expression levels of $\mathrm{HDACl}, \mathrm{CBP}$, and p300 in human colorectal cancer were investigated by immunohistochemistry. In situ hybridisation (ISH) and reverse transcription (RT)-PCR analyses were also carried out to confirm mRNA expression levels of these genes. Immunoreactivity was evaluated semiquantitatively using a staining index (SI). The relationships between the Sls and clinicopathological findings were analysed and survival curves were calculated using the Kaplan-Meier method and log-rank tests.

Results: The mean Sls for HDACl, CBP, and p300 in this series of tumours were much higher than those in normal colonic mucosa. The presence of $H D A C l$ and $C B P$ mRNAs on colorectal carcinoma cells as well as normal epithelial cells was confirmed by ISH analysis. A marked increase in p300 mRNA levels was detected in a majority of cases by RT-PCR. Among the patients with colorectal cancer, overexpression of p300 $(\mathrm{Sl}>11.9)$ correlated with a poor prognosis, whereas high CBP expression levels $(\mathrm{SI}>16.6)$ indicated longterm survival.

Conclusion: Results showed the up-regulation of these three histone-modifying molecules in this series of colorectal cancers and suggested that monitoring of CBP and p300 may assist prediction of the prognosis in patients with colorectal adenocarcinoma.
$\mathrm{H}$ istones are essential for packaging of DNA in eukaryotic cells. At the centre of the chromatin structure are highly conserved histone proteins that function as building blocks for packaging DNA into repeating nucleosomal units. ${ }^{1}$ Recently, the histone-modifying enzymes histone deacetylase (HDAC) and histone acetyltransferase (HAT) have been shown to be involved in transcriptional activation and repression. ${ }^{12}$

Eight HDAC isotypes have been cloned and classified into three distinct families (classes I, II, and III). ${ }^{2}$ As class I HDACs, which are related to the yeast transcriptional regulator RPD3, are expressed in most types of cell, they are thought to be involved in cellular differentiation and developmental processes. ${ }^{3}$ In particular, HDACl is believed to play a key role in the development of various human malignancies, such as acute myeloid leukaemia, breast cancer, prostatic cancer, lung cancer, and gastric cancer. ${ }^{4-10}$

CREB-binding protein (CBP) and p300, which are known as HAT molecules, are considered to be important transcriptional coactivators that act with other factors to regulate gene expression. ${ }^{11}$ In total, they have about $60 \%$ homology. ${ }^{12}$ Oncoprotein ElA activates HAT activity of $\mathrm{CBP},{ }^{13}$ while it disturbs HAT activity of $\mathrm{p} 300,{ }^{14}$ suggesting that CBP and p300 play different roles in cancer cells. ${ }^{15}$ These HATs regulate p53dependent transcription and function as pleiotropic coactivators that facilitate activation by a wide variety of sequencespecific transcription factors. ${ }^{11}$ Germline mutations in the $C B P$ gene have been reported in Rubinstein-Taybi disease, while somatic alterations have been detected in hepatocellular carcinoma and acute myeloid leukaemia. ${ }^{16-18}$ In addition, somatic mutations in the $p 300$ gene have been found in gastric cancer, colon cancer, glioblastoma and acute myeloid leukaemia. ${ }^{19-21}$ Thus, dysfunction of CBP and/or p300 is believed to contribute to tumourigenesis in various human malignancies.

In the current study, we evaluated expression levels of HDAC1, CBP, and p300 in human colorectal cancers in order to determine their roles in the development and progression of such tumours. Immunohistochemical, in situ hybridisation (ISH), and reverse transcription (RT)-PCR analyses were performed to investigate the expression levels of these HDAC/ HAT molecules and mRNAs in the colorectal carcinoma tissue. We then examined the relationships between HDAC/HAT expression levels and various clinicopathological findings.

\section{MATERIALS AND METHODS}

Tissue samples

Tissue samples were obtained from 64 patients with colorectal carcinoma who underwent surgical resection (table 1). The patients had not received any therapeutic agents or irradiation before surgery. Histological classification and clinicopathological staging were performed according to the general rules for clinical and pathological studies on cancer of colon, rectum and anus along with the International Union against Cancer Classification. ${ }^{22} 23$ The depth of tumour invasion was classified into four groups: none or minimal invasion within muscularis mucosa $(\mathrm{m})$, invasion of the submucosa $(\mathrm{sm})$, invasion of the proper muscle (mp), and beyond $\mathrm{mp}$ (ss, se, si, al, a2). A total of 64 patients with colorectal carcinoma were followed-up for 6 years; 17 cases were lost.

Abbreviations: CBP, CREB-binding protein; HAT, histone acetyltransferase; HDAC, histone deacetylase; ISH, in situ hybridisation; $\mathrm{SI}$, staining index 
Table 1 Relationship between clinicopathological findings and staining index (SI) for $\mathrm{HDACl}$ and $\mathrm{CBP} / \mathrm{p} 300$ proteins

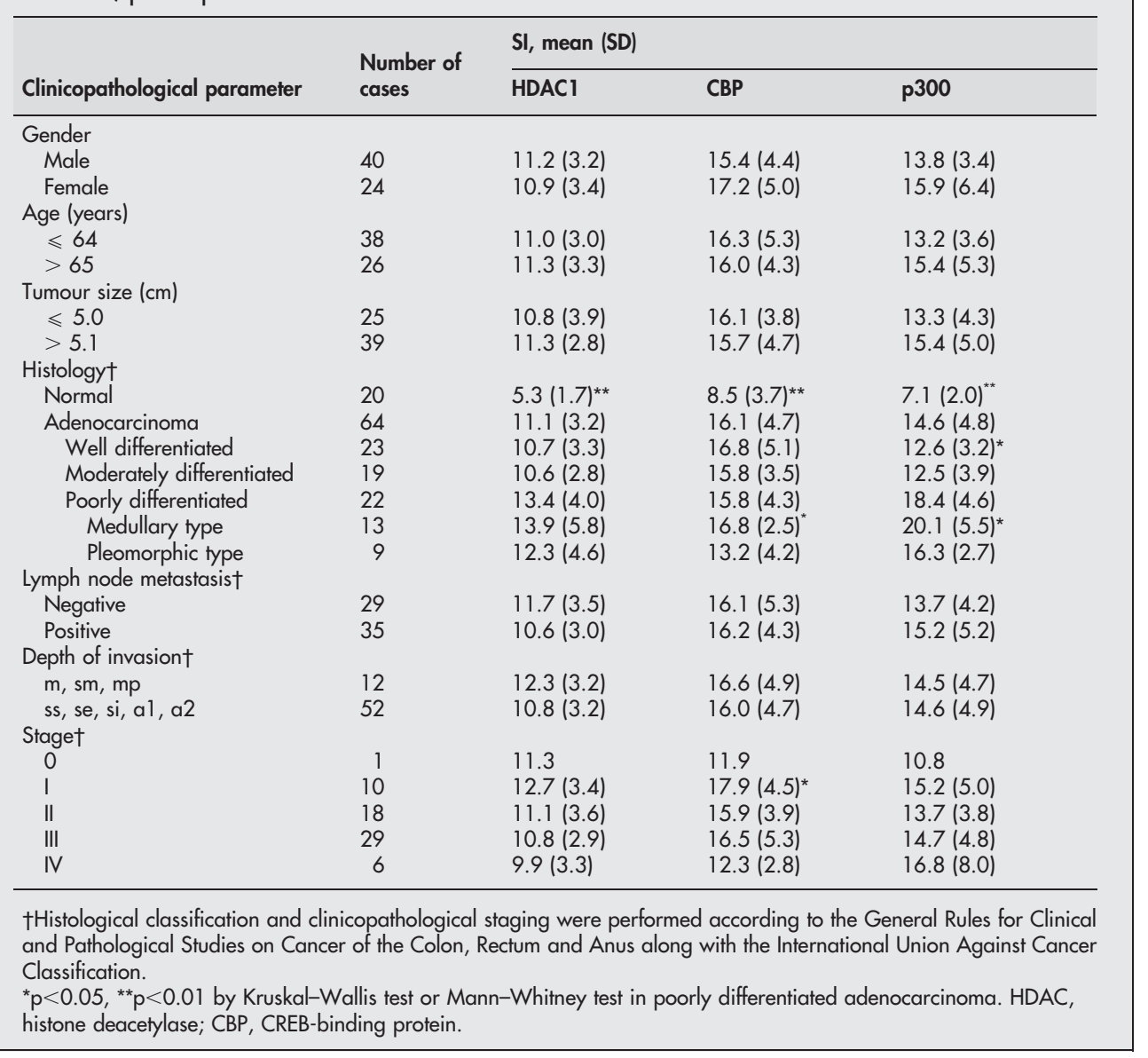

In addition, a total of 20 normal colonic mucosae from the resection margin of colorectal carcinomas were also used as controls. We also examined 17 fresh specimens of colorectal cancer and the corresponding normal colorectal mucosa for RTPCR analysis. These tissues were immediately frozen in liquid nitrogen and stored until use. Informed consent was obtained from all patients before surgery; this study was carried out in accordance with the ethics code for Human Experimentation, Yamagata University School of Medicine.

\section{Immunohistochemistry}

Immunohistochemistry was performed with an avidin-biotin complex immunoperoxidase technique as described previously. ${ }^{14}$ The primary antibodies against HDACl, CBP, and p300 were purchased from Santa Cruz Biotechnology (Santa Cruz, California, USA). After blocking of the endogenous peroxidase activity each $4 \mu \mathrm{m}$ of formalin-fixed and paraffinembedded tissue was placed in 0.1 mM EDTA ( $\mathrm{pH}$ 8.0, Nacalai, Kyoto, Japan) and microwaved for $23 \mathrm{~min}$ at $90^{\circ} \mathrm{C}$ to retrieve the antigenicity. The immunostaining was independently

Table 2 Intraobserver and interobserver variations

\begin{tabular}{llll}
\hline HDAC/HAT & No. of cases & $\begin{array}{l}\text { Intraobserver } \\
\text { variation }\end{array}$ & $\begin{array}{l}\text { Interobserver } \\
\text { variation }\end{array}$ \\
\hline HDACl & 64 & $p=0.947$ & $p=0.912$ \\
p300 & 64 & $p=0.972$ & $p=0.928$ \\
CBP & 64 & $p=0.933$ & $p=0.901$ \\
\hline
\end{tabular}

HDAC, histone deacetylase; HAT, histone acetyltransferase; CBP, CREBbinding protein. evaluated by two observers (KI and MY). The staining index (SI) was calculated as described previously. ${ }^{24}{ }^{25}$ Briefly, at least 50 fields in each tumour and non-tumour colorectal mucosa sections were evaluated to determine the proportion of tumour cells and the staining intensity of the nuclei in entire fields of the sections. The tumour cellularity was scored from 1 to 6 based on the proportion of tumour cells and the staining pattern of the section. The staining score was firstly estimated on a five-point scale $(0, \pm, 1+, 2+$, and $3+)$ and a score was obtained according to that intensity. ${ }^{24}{ }^{25}$ Where a homogeneous pattern was obtained, a visual estimate was made of both the predominant intensity and the minority value. The SI was calculated by multiplying the cellularity and staining scores. ${ }^{24} 25$ Finally, the SI for a section was calculated as the mean of the SIs of all the fields examined in each section. To confirm the reproducibility of the result, all the sections were scored at least three times.

\section{ISH analysis}

Twenty of 64 colon cancers were examined by ISH for $\mathrm{HDACl}$ and $C B P$ mRNAs to confirm the presence of their messages on cancer cells. The antisense oligonucleotide probes, HDACl and CBP, were as follows: HDAC1, 5'-GAG GAG AAG CCA GAA GCC AAA GGG GTC AAG GAG GAG GTC AAG TTG GC-3'; CBP, 5'GAA CTG TCC CTG GTT GGT GAT ACC ACG GGA GAC ACA CTA GAA AAG TTT GTG GAG GGT TTG-3'. The probes were hybridised to entire mRNA transcript of the HDACl and $C B P$ genes, respectively, including the $5^{\prime}$ and $3^{\prime}$ untranslated regions. Each $4 \mu \mathrm{m}$ of formalin-fixed (within $12 \mathrm{~h}$ ) and paraffin-embedded sections were deparaffinised and rehydrated. After digestion with $0.4 \%$ pepsin, the specimens were 
Table 3 Results of univariate analysis

\begin{tabular}{lllr}
\hline Predictive variables & HR & Cl & p-Value \\
\hline HDAC1 SI: $>10.7$ (baseline $\leqslant 10.6$ ) & 1.725 & 0.219 to 4.426 & 0.2236 \\
p300 SI: $>11.9$ (baseline $\leqslant 11.8$ ) & 3.560 & 1.021 to 12.410 & 0.0464 \\
CBP SI: $\leqslant 16.6$ (baseline $>16.7$ ) & 4.539 & 1.095 to 14.293 & 0.0356 \\
Histological differentiation: poor (baseline well/ & 7.331 & 2.696 to 19.940 & $<0.0001$ \\
moderately) & & & \\
Lymph node metastasis: positive (baseline negative) & 6.346 & 1.748 to 20.626 & 0.0036 \\
Stage: III, IV (baseline 0, I, II) & 5.326 & 1.549 to 18.316 & 0.008 \\
Tumour size (cm): $\geq 5.0$ (baseline <5.0) & 4.226 & 1.238 to 14.923 & 0.0186 \\
Depth of invasion: T4 (baseline Tis, T1, T2, T3) & 6.875 & 1.066 to 49.579 & 0.0496 \\
Age (years): $\geqslant 65$ (baseline $<64)$ & 2.026 & 0.829 to 6.925 & 0.0605 \\
Gender: male (baseline female) & 0.725 & 0.429 to 1.825 & 0.4425 \\
\hline
\end{tabular}

$\mathrm{HR}$, hazard ratio; HDAC, histone deacetylase; CBP, CREB-binding protein; SI, staining index.

Table 4 Results of multivariate analysis

\begin{tabular}{llll}
\hline Predictive variables & HR & CI & p-Value \\
\hline p300 SI: $>11.9$ (baseline $<11.8$ ) & 4.118 & 1.049 to 16.170 & 0.0425 \\
CBP SI: $<16.6$ (baseline $>16.7$ ) & 4.026 & 1.133 to 14.301 & 0.0313 \\
Lymph node metastasis: positive (baseline negative) & 4.693 & 1.295 to 17.007 & 0.0186 \\
Age (years): $\geq 65$ (baseline $<64$ ) & 0.501 & 0.158 to 1.590 & 0.2410 \\
Gender: male (baseline female) & 0.851 & 0.284 to 2.556 & 0.7742 \\
\hline
\end{tabular}

HR: hazard ratio, $\mathrm{Cl}: 95 \%$ confidence interval, $P$ : P value, The values of $\mathrm{p} 300$ and CBP SI, and lymph node metastasis were adjusted for depth of invasion, age, and gender.

covered with hybridisation solution containing fluorescein isothiocyanate (FITC)-labelled DNA probes $(500-2000 \mathrm{ng} / \mathrm{ml}$ ) and hybridised at $55^{\circ} \mathrm{C}$ overnight. Two control studies were carried out to test the specificities of the oligonucleotide probes and the stainability as previously described. ${ }^{26}$

\section{RT-PCR analysis of p300 mRNA in human colorectal cancer}

Expression of $p 300$ mRNA in 17 fresh specimens of colorectal cancer ( 7 cases of well, 6 of moderately, and 4 of poorly differentiated adenocarcinoma) was examined. RT-PCR was performed with One Step RT-PCR assay kit (Qiagen). ${ }^{26}$ Primer sets used for RT-PCR amplification were as follows: $p 300$ forward, 5'-AAA CCC ACC AGA TGA GGA C-3'; p300-reverse, 5'-TAT GCA CTA GAT GGC TCC GCA G-3'. As a control, hypoxanthine-phosphoribosyl-transferase (HPRT) level was also analysed (forward, 5'-CGG GGG ACA TAA AAG GTT AT-3'; reverse, 5' -CCA CTT TCG CTG ATG ACA C-3'.

\section{Statistical analysis}

Both intraobserver and interobserver reproducibilities were evaluated simultaneously using the Kruskal-Wallis test. The
Mann-Whitney non-parametric test was used to compare the staining index of pairs of subjects and the Kruskal-Wallis test was used to for categorical data. Correlation between the indexes was determined by a simple linear regression test. Survival curves were calculated using the Kaplan-Meier method and analysed by the log-rank test. The influence of each variable on survival was assessed by the Cox proportional hazards model. A value of $\mathrm{p}<0.05$ was considered to be significant.

\section{RESULTS}

\section{Expression of HDAC 1 protein and mRNA in colorectal cancers}

Table 1 summarises the results of the immunohistochemical analyses; tables 2,3 , and 4 , respectively, summarise information on intraobserver/interobserver variations and the results of the univariate and multivariate analyses.

Expression of HDACl protein was detected in the nuclei of both neoplastic and non-neoplastic cells, with a mean HDACl SI of 11.1 (3.2) (range 3.6-15.3) (fig 1A). The mean HDACl SI in the carcinomas was significantly higher than that in the corresponding normal mucosae $(\mathrm{p}<0.01)$, but no relationship
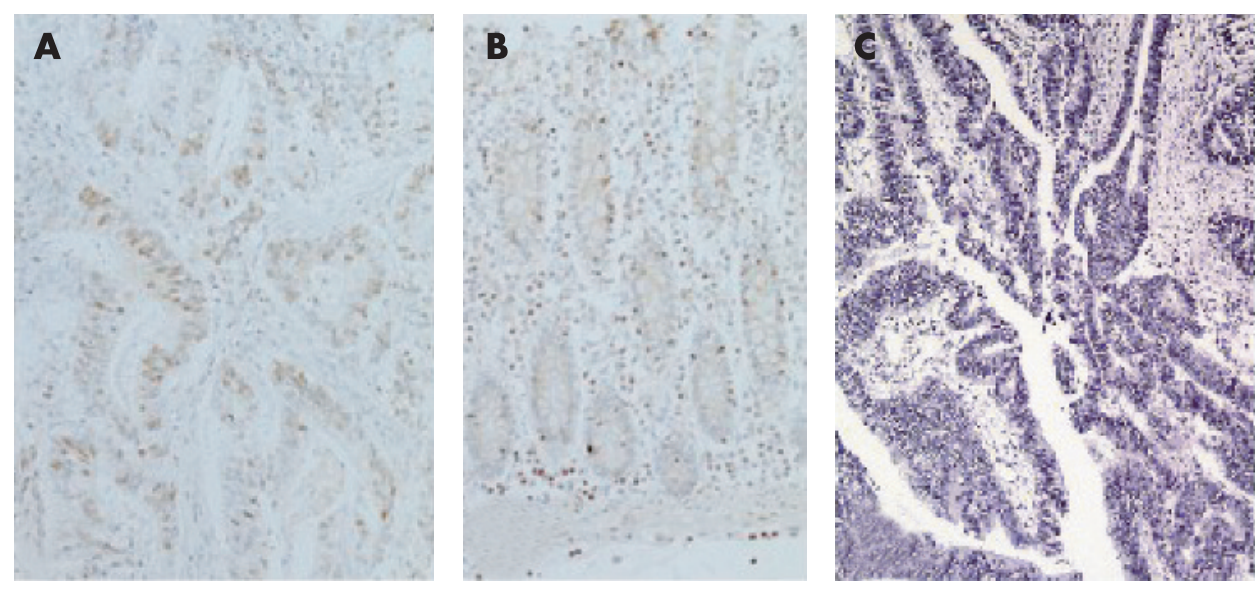

Figure 1 Expression of $\mathrm{HDACl}$ protein and mRNA in cancer tissue and the corresponding normal mucosa. Immunohistochemical detection of $\mathrm{HDACl}$ protein in cancer tissue $(A)$ and the corresponding normal mucosa (B). The $\mathrm{HDACl} \mathrm{SI}$ in the carcinoma was significantly higher than in the normal mucosa. (C) In situ hybridisation analysis of $\mathrm{HDACl}$ mRNA in well differentiated adenocarcinoma of colon. HDAC1 mRNA expression in cancer tissue and normal mucosa was detected on the nuclei. HDAC, histone deacetylase. 

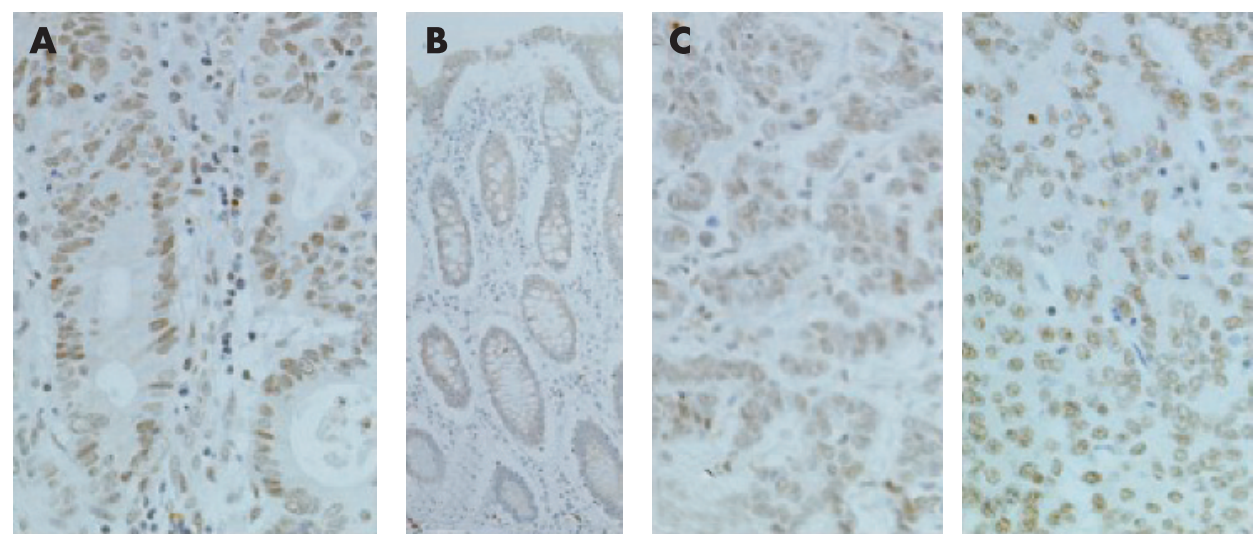

Figure 2 Expression of CREB-binding protein (CBP) and mRNA in cancer tissue and the corresponding normal mucosa. Immunohistochemical detection of CBP protein in well differentiated adenocarcinoma (A) and the corresponding normal mucosa (B). (C)

Immunohistochemical detection of CBP protein in poorly differentiated adenocarcinoma. CBP expression in the medullary tumour (right) was higher than in the pleomorphic tumour (left). (D) In situ hybridisation of CBP mRNA in moderately differentiated adenocarcinoma of colon.

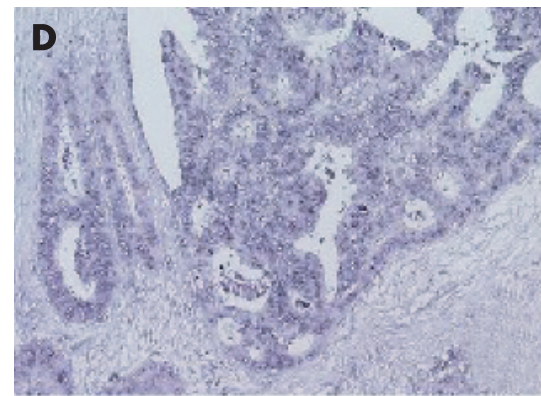

with any of the clinicopathological findings, such as gender, age, tumour size, differentiation, and progression was observed. Similarly, we confirmed that the incidence of high expression levels of HDACl mRNA was greater in the cancer cells than in normal epithelial cells by ISH analysis (fig lB).

\section{Expression of CBP protein and mRNA in colorectal cancers}

The CBP SI ranged from 10.3 to 21.9 (mean 16.1 (4.7)) and was significantly higher in the carcinomas (fig 2A) than in the normal mucosae $(\mathrm{p}<0.01)$. Among poorly differentiated adenocarcinomas, the CBP SI for medullary carcinomas (16.8 (2.5), $\mathrm{n}=13$ ) was higher than that for pleomorphic carcinomas (13.2 $(4.2), \mathrm{n}=9) \quad(\mathrm{p}<0.05$; fig $2 \mathrm{~B})$. A significant difference was observed between stages I and IV $(p=0.05)$. We also detected the presence of $C B P$ mRNA levels in this series of colorectal carcinomas by ISH analysis (fig 2C).

\section{Expression of $\mathrm{p} 300$ protein and mRNA in colorectal cancers}

The mean p300 SI of the tumours was 14.6 (4.8) (range 5.123.0), which was significantly higher than that in the normal mucosae $(p<0.01)$ (fig 3A). Furthermore, the mean p300 SI in poorly differentiated carcinomas was 18.4 (4.6), indicating an
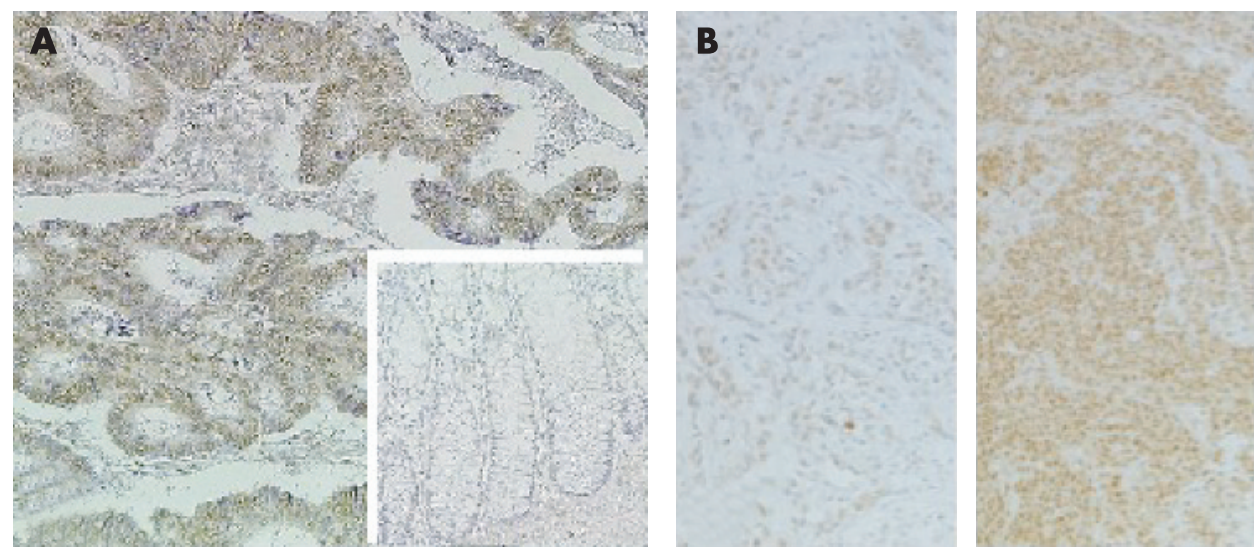

Figure 3 Expression of p300 protein in cancer tissue and the corresponding normal mucosa. (A) p300 protein was more highly expressed in the carcinoma tissues than in the normal mucosae (inset). (B) Immunohistochemical detection of p300 in poorly differentiated adenocarcinoma. The Sls of the pleomorphic tumour was lower than in the medullary tumour.

\begin{tabular}{|c|c|c|c|c|c|c|c|c|c|c|c|c|c|c|}
\hline & \multicolumn{2}{|c|}{ Case 1} & \multicolumn{2}{|c|}{ Case 2} & \multicolumn{2}{|c|}{ Case 3} & \multicolumn{2}{|c|}{ Case 4} & \multicolumn{2}{|c|}{ Case 5} & \multicolumn{2}{|c|}{ Case 6} & \multicolumn{2}{|c|}{ Case 7} \\
\hline & $\mathrm{N}$ & $\mathrm{T}$ & $N$ & $\mathrm{~T}$ & $\mathrm{~N}$ & $\mathrm{~T}$ & $N$ & $\mathrm{~T}$ & $N$ & $\mathrm{~T}$ & $N$ & $\mathrm{~T}$ & $\mathrm{~N}$ & $\mathrm{~T}$ \\
\hline p300 & - & - & - & - & 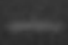 & - & $=$ & $=$ & - & $=$ & - & - & - & - \\
\hline PRT & 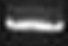 & $=$ & $=$ & $=$ & 2 & - & 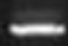 & $=$ & $=$ & - & 2 & L & $=$ & - \\
\hline
\end{tabular}

Figure 4 RT-PCR analysis of p300 mRNA in representative seven cases of human colon cancer. As a control, expression levels of HPRT mRNA in each case were also shown. Cases 1-5, well and moderately differentiated adenocarcinoma. Cases 6 and 7 , poorly differentiated adenocarcinoma. $N$, normal colon mucosa, T, tumour sample. 

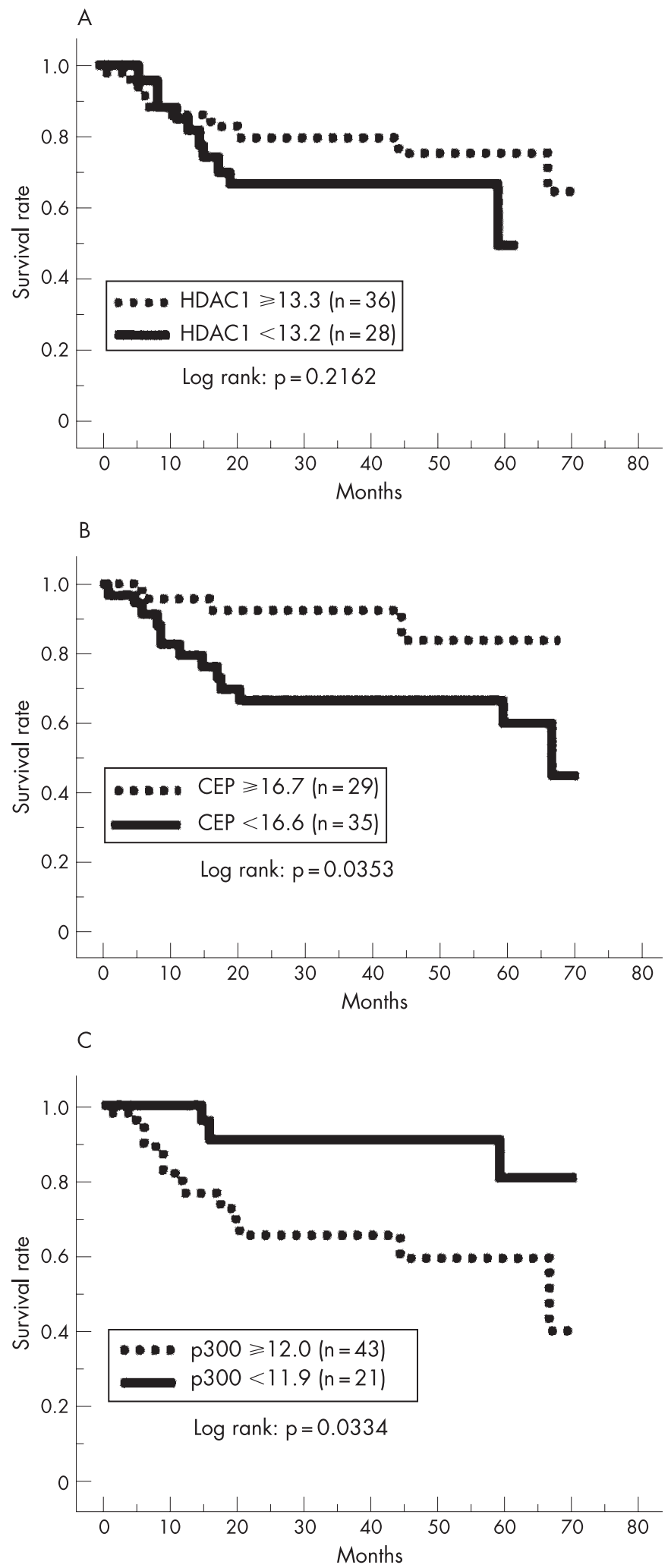

Figure 5 Kaplan-Meier survival curves of patients with colorectal carcinoma. (A) Subdivided according to HDACl status. No significant difference was shown between the two groups. (B) Subdivided according to $\mathrm{CBP}$ status. Overall survival was significantly higher in patients with $\mathrm{CBP}$ overexpression. (C) Subdivided according to p300 status. Overall survival was significantly lower in patients with p300 overexpression. HDAC, histone deacetylase; CBP, CREB-binding protein.

increase compared with well and moderately differentiated adenocarcinomas. Among poorly differentiated adenocarcinomas, the p300 SI for medullary carcinomas (20.1 (5.5)) was
Take-home messages

- Overexpression of p300 is an indicator of poor prognosis of patients with colorectal cancer.

- High CREB-binding protein expression correlates with significantly better survival.

higher than that for pleomorphic carcinomas (16.3 (2.7)) $(\mathrm{p}<0.05$; fig $3 \mathrm{~B})$. A marked increase in $p 300$ mRNA levels was detected in $13(76 \%)$ of 17 specimens by RT-PCR (fig 4 ). Four cases of poorly differentiated adenocarcinomas showed higher p300 mRNA expression levels than their corresponding normal mucosae.

\section{Relationship between HDAC/HAT protein expression and clinicopathological findings}

An univariate Cox regression analysis showed that overexpression $($ SI $>11.9$ ) of p300, reduction of CBP (SI $<16.6$ ), poorly differentiated histology, lymph node metastasis, TNM stage, tumour size, and depth of invasion were all significant prognostic factors (table 3). Figure 5 shows the Kaplan-Meier survival curves for subgroups of patients. There was no statistical significance between HDACl overexpression and prognosis (fig 5A). However, overall survival was significantly higher in patients with CBP overexpression (fig 5B), and lower in patients with p300 overexpression (fig 5C). A Cox multivariate regression analysis showed that p300 overexpression, reduced CBP expression, and lymph node metastasis were independent negative prognostic factors, after adjustment for the depth of tumour invasion and the age and sex of the patient (table 4).

\section{DISCUSSION}

To the best of our knowledge, this is the first report demonstrating the overexpression of HDACl at both the transcriptional and translational levels in colorectal carcinomas. Our results are in general agreement with those of a previous study on HDACl expression levels in gastric cancers. ${ }^{27}$ Since overexpression of HDACl causes down-regulation of tumour suppressor genes, such as p53 and VHL, ${ }^{28}$ these data imply that raised HDACl expression might lead to hypoacetylation of histone and subsequent silencing of several tumour suppressor genes in colorectal cancers. In support of this idea, the physiological consequence of hypoacetylation due to deletion or inactivation of HAT is a high incidence of malignant tumours: our present data also indicate up-regulation of p300 expression in colorectal tumours.

Histone modification due to reversible acetylation by HDAC/ HAT is believed to play a significant role in controlling gene expression, ${ }^{28-31}$ and HDAC inhibitors including butyrate, trichostatin A, and others have antitumour activity against various human malignancies, such as breast and prostate cancers as well as colon cancer. ${ }^{4-632-36}$ Studies in which human tumour lines are implanted into nude mice also indicate that HDAC inhibitors may be novel therapeutic agents for cancer treatment. ${ }^{7}$ The present study showed the frequent HDAClexpression in colonic adenocarcinoma tissues compared with corresponding normal mucosae. This evidence indicates the possibility of availability of HDAC inhibitors for colonic cancer.

In the present study both CBP and p300 were overexpressed in adenocarcinoma tissues compared with normal mucosae. Furthermore, overall survival was good in patients with CBP overexpression and poor in those with p300 overexpression. A Cox multivariate regression analysis also showed the significance of the p300 overexpression and reduced CBP expression. 
Because there is a high degree of structural homology between CBP and p300, it may seem that the present data cannot be explained. However, accumulating evidence indicates that CBP and p300 are not completely redundant but have unique roles; these functional differences could be due to differential association with other proteins or differences in substrate specificity between these acetyltransferases. ${ }^{37}{ }^{38}$ For example, CBP and p300 play very distinct roles in survivin gene transcription. ${ }^{39}$ In humans mutant huntington represses CBP, but not p300, by binding and protein degradation. ${ }^{40}$ Interestingly, CBPl directly associates with p300 by binding to the PXDLS motif in the bromodomain of p300 and blocks the accessibility of p300 to histones, thus repressing p300-mediated histone acetylation and transcriptional activation. ${ }^{41}$ Consequently, the evidence of p300 overexpression and reduced CBP expression in colonic cancer in the present study may indicate enhanced p300-mediated histone acetylation and transcriptional activation.

In conclusion, the present study indicated that expression levels of HDAC/HAT-associated proteins HDACl, CBP, and p300 were up-regulated in human colorectal cancers. Overexpression of p300 is an indicator of poor prognosis of these patients; conversely, high CBP expression correlates with significantly better survival. Further studies will be needed to clarify the downstream mechanisms involved in controlling the biological behaviour of colorectal carcinomas via histone-modifying molecules.

\section{ACKNOWLEDGMENTS}

We thank Dr Ikeda E (Yamagata Prefectural Central Hospital) for providing the surgical specimens.

\section{Authors' affiliations}

Katsuyoshi Ishihama, Mitsunori Yamakawa, Shuho Semba, Department of Pathology, Yamagata University School of Medicine, Yamagata, Japan Hiroaki Takeda, Sumio Kawata, Second Department of Internal Medicine, Yamagata University School of Medicine, Yamagata, Japan

Seishi Kimura, Wataru Kimura, First Department of Surgery, Yamagata University School of Medicine, Yamagata, Japan

Competing interests: None declared.

\section{REFERENCES}

1 Strahl BD, Allis CD. The language of covalent histone modifications. Nature 2000;403:41-5.

2 Fischle W, Dequiedt F, Hendzel MJ, et al. Enzymatic activity associated with class II HDACs is dependent on a multiprotein complex containing HDAC3 and SMRT/ N-CoR. Mol Cell 2002;9:45-57.

3 Taunton J, Hassig CA, Schreiber SL. A mammalian histone deacetylase related to the yeast transcriptional regulator Rpd3. Science 1996;272:408-11.

4 Maeda T, Towatari M, Kosugi $H$, et al. Up-regulation of costimulatory/adhesion molecules by histone deacetylase inhibitors in acute myeloid leukemia cells. Blood 2000;96:3847-56.

5 Richon VM, Sandhoff TW, Rifkind RA, et al. Histone deacetylase inhibitor selectively induces p21WAF1 expression and gene-associated histone acetylation. Proc Natl Acad Sci USA 2000;97:10014-19.

6 Vigushin DM, Ali S, Pace PE, et al. Trichostatin A is a histone deacetylase inhibitor with potent antitumor activity against breast cancer in vivo. Clin Cancer Res $2001 ; 61: 971-6$.

7 Butler LM, Agus DB, Scher HI, et al. Suberoylanilide hydroxamic acid, an inhibitor of histone deacetylase, suppresses the growth of prostate cancer cells in vitro and in vivo. Cancer Res 2000;60:5165-70

8 Yarden RI, Brody LC. BRCA1 interacts with components of the histone deacetylase complex. Proc Natl Acad Sci USA 1999;96:4983-8.

$9 \operatorname{Kim}$ MS, Kwon HJ, Lee YM, et al. Histone deacetylases induce angiogenesis by negative regulation of tumor suppressor genes. Nat Med 2001;7:437-43.
10 Suzuki T, Yokozaki $\mathrm{H}$, Kuniyasu $\mathrm{H}$, et al. Effect of trichostatin $\mathrm{A}$ on cell growth and expression of cell cycle- and apoptosis-related molecules in human gastric and oral carcinoma cell lines. Int J Cancer 2000;88:992-7.

11 Shikama N, Lee CW, France S, et al. A novel cofactor for p300 that regulates the p53 response. Mol Cell 1999;4:365-76.

12 Arany Z, Sellers WR, Livingston DM, et al. E1A-associated p300 and CREBassociated CBP belong to a conserved family of coactivators. Cell 1994;77:799-800.

13 Ait-Si-Ali S, Ramirez S, Barre FX, et al. Histone acetyltransferase activity of CBP is controlled by cycle-dependent kinases and oncoprotein E1A. Nature 1998;396:184-6.

14 Chakravarti D, Ogryzko V, Kao HY, et al. A viral mechanism for inhibition of p300 and PCAF acetyltransferase activity. Cell 1999;96:393-403.

15 Kawasaki H, Eckner R, Yao TP, et al. Distinct roles of the co-activators p300 and CBP in retinoic-acid-induced F9-cell differentiation. Nature 1998;393:284-9

16 Murata T, Kurokawa R, Krones A, et al. Defect of histone acetyltransferase activity of the nuclear transcriptional coactivator CBP in Rubinstein-Taybi disease. Hum Mol Genet 2001;91:1154-60.

17 Petrij F, Giles RH, Dauwerse HG, et al. Rubinstein-Taybi syndrome caused by mutations in the transcriptional co-activator CBP. Nature 1995;376:348-51.

18 Sakai K, Nagahara H, Abe K, et al. Loss of heterozygosity on chromosome 16 in hepatocellular carcinoma. J Gastroenterol Hepatol 1992;7:288-92.

19 Muraoka M, Konishi M, Kikuchi-Yanoshita R, et al. p300 gene alterations in colorectal and gastric carcinomas. Oncogene 1996;12:1565-9.

20 Borrow J, Stanton VP Jr, Andresen JM, et al. The translocation $t(8 ; 16)(p 11 ; p 13)$ of acute myeloid leukaemia fuses a putative acetyltransferase to the CREBbinding protein. Nat Genet 1996;14:33-41.

21 Giles RH, Peters DJ, Breuning MH. Conjunction dysfunction: CBP/p300 in human disease. Trends Genet 1998;14:178-83.

22 Japanese Society for Cancer of the Colon and Rectum. General rules for clinical and pathological studies on cancer of colon, rectum and anus. 6th edn. Tokyo: Kanehara, 1998.

23 Sobin LH, Wittekind C. TNM classification of malignant tumors. 5th edn. New York: Wiley-Liss, 1997.

24 Handa K, Yamakawa M, Takeda $\mathrm{H}$, et al. Expression of cell cycle markers in colorectal carcinoma: superiority of cyclin $A$ as an indicator of poor prognosis. Int J Cancer 1999;84:225-33.

25 King RJ, Coffer Al, Gilbert J, et al. Histochemical studies with a monoclonal antibody raised against a partially purified soluble estradiol receptor preparation from human myometrium. Cancer Res 1985;45:5728-33.

26 Tsuge K, Takeda H, Kawada S, et al. Characterization of dendritic cells in differentiated thyroid cancer. J Pathol 2005;205:565-76.

27 Choi JH, Kwon HJ, Yoon Bl, et al. Expression profile of histone deacetylase 1 in gastric cancer tissues. Jpn J Cancer Res 2001;92:1300-4.

28 Di Padova M, Bruno T, De Nicola F, et al. Che-1 arrests human colon carcinoma cell proliferation by displacing $\mathrm{HDACl} 1$ from the $\mathrm{p} 21 \mathrm{WAF1} / \mathrm{CIP1}$ promoter. J Biol Chem 2003;278:36496-504.

29 lonov Y, Matsui S, Cowell JK. A role for p300/CREB binding protein genes in promoting cancer progression in colon cancer cell lines with microsatellite instability. Proc Natl Acad Sci USA 2004;101:1273-8.

30 Murphy M, Ahn J, Walker KK, et al. Transcriptional repression by wild-type p53 utilizes histone deacetylases, mediated by interaction with mSin3a. Genes Dev 1999;13:2490-501

31 Hayashi $\mathrm{R}$, Wada $\mathrm{H}$, Ito $\mathrm{K}$, et al. Effects of glucocorticoids on gene transcription. Eur J Pharmacol 2004;500:51-62.

32 Mclntyre A, Gibson PR, Young GP. Butyrate production from dietary fibre and protection against large bowel cancer in a rat model. Gut 1993;34:386-91.

33 Archer S, Meng S, Wu J, et al. Butyrate inhibits colon carcinoma cell growth through two distinct pathways. Surgery 1998;124:248-53.

34 Barnard JA, Warwick G. Butyrate rapidly induces growth inhibition and differentiation in HT-29 cells. Cell Growth Differ 1993;4:495-501.

35 Marks PA, Richon VM, Breslow R, et al. Histone deacetylase inhibitors as new cancer drugs. Curr Opin Oncol 2001;13:477-83.

36 Lau OD, Kundu TK, Soccio RE, et al. HATs off: selective synthetic inhibitors of the histone acetyltransferases p300 and PCAF. Mol Cell 2000;5:589-95.

37 Kalkhoven E. CBP and p300: HATs for different occasions. Biochem Pharmacol 2004;68: 11 145-55.

38 lyer NG, Özdag H, Caldas C. p300/CBP and cancer. Oncogene 2004;23:4225-31.

$39 \mathrm{Ma} \mathrm{H}, \mathrm{Nguyen} \mathrm{C}$, Lee KS, et al. Differential roles for the coactivators CBP and p300 on TCF/beta-catenin-mediated survivin gene expression. Oncogene 2005;24:3619-31.

40 Cong SY, Pepers BA, Evert BO, et al. Mutant huntingtin represses CBP, but not p300, by binding and protein degradation. Mol Cell Neurosci 2005;30:12-23

$41 \mathrm{Kim}$ JH, Cho EJ, Kim ST, et al. CtBP represses p300-mediated transcriptional activation by direct association with its bromodomain. Nat Struct Mol Biol 2005;12:423-8. 